\title{
The occupational role of dental conditions among a consecutive sample of Spanish workers
}

\author{
Javier Montero ${ }^{1}$, Antonio López-Valverde ${ }^{2}$, Yolanda Clemot ${ }^{3}$, Manuel Bravo ${ }^{4}$ \\ ${ }^{1}$ Tenured lecturer of Prosthodontics. Department of Surgery. Faculty of Medicine. University of Salamanca. Spain \\ ${ }^{2}$ Associate Professor of Periodontics. Department of Surgery. Faculty of Medicine. University of Salamanca. Spain \\ ${ }^{3}$ Dental Hygienist. Granada. Spain \\ ${ }^{4}$ Professor of Community and Preventive Dentistry. University of Granada. Spain
}

Correspondence:

Clínica Odontológica. Facultad de Medicina.

C/ Alfonso X el Sabio S/N.

Campus Miguel de Unamuno.

C.P: 37007. Salamanca. Spain.

javimont@usal.es

Received: 26/08/2010

Accepted: 08/12/2010

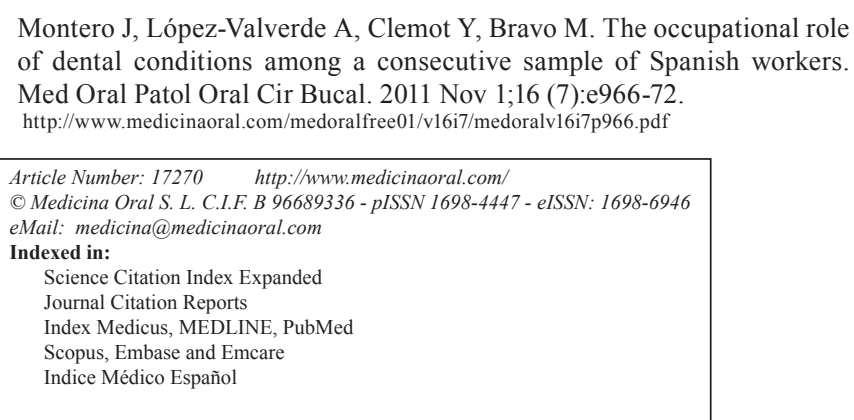

\begin{abstract}
Objectives: To assess the occupational impact of the mouth in terms of days of work loss in the last year and the perception of the working performance disturbance because of the oral conditions. Study design: A consecutive sample ( $\mathrm{n}=269)$ of the Regional Government staff of the province of Granada (Spain) was recruited. Participants were asked about work loss related to health problems in the past 12 months, capturing the aetiological entities, the frequency of the work absent and the total days loss. Also subjects reported if they believed that mouth affects their occupational performance, and if they have perceived difficulties for carrying out work because of the mouth. Data on sociodemographic, behavioural and clinical factors were also gathered. Chi-squared test, Odds ratio (OR) and relative risk (RR) of perceived occupational role were used to quantify the effect of the modulating factors. Results: Almost $40 \%$ of individuals were absent from work during the last year spending on average 5.4 days for recovering. Colds and musculoskeletal pathology were the major causes of sick leave. Dental disease caused short work absences (4 days on average) only in $2.8 \%$ of participants. However most of workers $(62.5 \%)$ considered mouth to influence their occupational performance, mainly because of the pain-related events (61.7\%), but only $4.1 \%$ of workers reported difficulties in carrying out their work in the past 12 months. Females ( $R R=1.3$ ), participants attending regular dental visits $(R R=1.4)$ and denture wearers $(R R=2.5)$ were shown to have significantly higher risk of perceiving an occupational role of the mouth. Those workers reporting that mouth influences their work have significantly poorer oral health than counterparts. Conclusions: Most workers considered that mouth influences their occupational performance but dental disease has demonstrated to be a minor occupational cause of sick leave in terms of prevalence and magnitude of work loss.
\end{abstract}

Key words: Absenteeism, oral health, sick leave. 


\section{Introduction}

According to the last National Oral Health Survey performed in Spain, 1 in 3 Spanish adults or elderly reported experiencing oral pain as a result of oral disorders, sometimes or more frequently, in the previous year. In the same period, 1 in 5 Spanish adults and 1 in 4 Spanish elderly suffered from eating difficulties because of problems with their mouth, teeth or dentures (1). However to date research on the impact of dental conditions in the occupational performance is limited $(2,3)$. The impact of oral health problems on society has been defined as the outcomes related to limitations in role performance and functional capabilities. At this societal level, it has been estimated for the U.S. that there were 6.8 million acute dental conditions resulting in 5.1 million work loss days in 1979 (4). Ten years after, it was estimated that 148.000 hours of work were lost per 100.000 workers because of dental visits or problems in U.S (2). This study estimated that one in four of the workers reported and episode of work loss in the past 12 months related to dental visits or problems. In Europe, Miller's report (1978) on dental pain in Great Britain also found considerable work absence associated with dental conditions, in that $30 \%$ of adult male patients lost wages due to dental clinic appointments (5). In Spain, to our knowledge, there have not been conducted any study focussing on the impact of oral health in the occupational performance, capturing workers perception about the occupational role of the oral health and the days of work loss by oral reasons. This study aims to assess the occupational impact of the mouth in terms of days of work loss in the last year and the perception of the working performance disturbance because of the oral conditions.

\section{Materials and Methods}

A consecutive sample of healthy Andalusia's Government staff visiting the Employment Risk Prevention Centre in Granada (Spain) for a routine medical checkup was invited to take part in this study. All participants were briefed about the purpose and process of the study and the approved written consent was obtained. Individuals seeking dental treatment or diagnosis for acute dental problems were excluded in order to capture the occupational role of the mouth in non dental patients. Sociodemographic data (age, sex, social class, place of residence) and behavioural data (brushing habits, last dental visit and dental visits pattern) were captured before the oral examinations were performed for assessing caries, periodontal and prosthetic status. Moreover participants were asked about some subjective perceptions: i.e. perception about mouth affecting the occupational performance, perceived difficulties for carry out work because of the mouth, teeth or dentures in the last year. Those participants reporting occupational role of the mouth were asked about why they think that mouth influences their occupational performance in an openended question. The answers were then grouped together according to the construct referred. Furthermore health-related absenteeism, the cause of such absenteeism and the days of work loss were also gathered. Total days lost for each cause was calculated multiplying the number of subjects affected by the mean of days lost. This value was also estimated per 100 workers.

\section{-Data analysis}

The Statistical Package for Social Sciences (SPSS) v.15 (SPSS Inc., Chicago, IL) was used for the statistical analyses taking the cut-off level for statistical significance at 0.05 . Quantitative variables were expressed as mean \pm standard deviation, and were analyzed using Student $\mathrm{T}$ test. Chi-squared test, Odds ratio (OR) and relative risk (RR) of perceived occupational role were used to quantify the effect of the sociodemographic, behavioural and clinical factors.

\section{Results}

\section{- Sample description}

For a three-week period of data collection, 295 healthy workers visited the Center, 269 of whom participated in the study (91.5\%) and 26 were drop out, but all were similar in terms of socio-demographic characteristics. Table 1 shows the descriptive characteristics of the sample $(\mathrm{n}=269)$. The mean age of participants was $45.1 \pm$ 9.3 years (mean \pm standard deviation), $45.4 \%$ were male, $83.6 \%$ were skilled workers and $57.2 \%$ live in Granada capital. In behavioural terms $93.3 \%$ of subjects brushed their teeth at least once a day and $33.5 \%$ visited routinely the dentist at least once a year.

On clinical examination (Table 1), participants mostly showed a good state of oral health. Most subjects (90.3\%) were dentate with a mean of $6.4 \pm 2.2$ posterior occlusal units and $5.8 \pm 0.9$ anterior occlusal units. The sample had a mean of $26.5 \pm 4.1$ standing natural teeth with 17.9 \pm 5.6 healthy non-restored teeth. The Decayed, Missing and Filling teeth (DMFT) index was $10.7 \pm 4.9$, with $3.2 \pm 2.5$ being decayed, $3.2 \pm 3.6$ missing and $4.3 \pm$ 3.5 filling teeth. The periodontal status showed a Community Periodontal Index (CPI) score of zero in $3.1 \pm$ 2.2 sextants.

- Health-related absenteeism and perceived occupational role of the mouth

Almost $40 \%$ of individuals were absent from work during the last year, spending on average 5.4 days for recovering (Table 2). The majority of them were absent at work because of colds and spent 2.5 days for recovering. Musculoskeletal pathology was behind the 23.1\% of absents workers, needing 33.9 days for return to work. Also cardiovascular disease was responsible of the $5.6 \%$ of the sick leave, and the mean period to return to work was 24.3 days. Dental disease caused short 
Table 1. Descriptive characteristics of the sample $(n=269)$.

\begin{tabular}{|c|c|c|}
\hline Age* & & $\%$ \\
\hline & $<34$ years & 14.5 \\
\hline & $35-44$ years & 31.6 \\
\hline & $45-54$ years & 36.8 \\
\hline & $55-65$ years & 23.4 \\
\hline \multicolumn{3}{|l|}{ Sex } \\
\hline & Male & 45.4 \\
\hline & Female & 54.6 \\
\hline \multicolumn{3}{|l|}{ Social Class $^{\mathrm{a}}$} \\
\hline & High & 4.8 \\
\hline & Medium & 78.8 \\
\hline & Low & 16.4 \\
\hline \multicolumn{3}{|l|}{ Brushing habits } \\
\hline & 3 times per day & 33.5 \\
\hline & Twice per day & 33.8 \\
\hline & Once per day & 26.0 \\
\hline & $\leq$ once per week & 6.7 \\
\hline \multicolumn{3}{|l|}{ Place of residence } \\
\hline & Urban & 57.2 \\
\hline & Peri-urban & 22.3 \\
\hline & Rural & 20.4 \\
\hline \multicolumn{3}{|l|}{ Last dental visit } \\
\hline & $<3$ months & 16.4 \\
\hline & Within 3 months- 1 year & 43.5 \\
\hline & Within $1-2$ years & 17.1 \\
\hline & Within 2-5 years & 13.8 \\
\hline & $>5$ years & 9.3 \\
\hline \multicolumn{3}{|l|}{ Perceived dental needs } \\
\hline & Yes & 44.4 \\
\hline & No & 55.6 \\
\hline \multicolumn{3}{|l|}{ Pattern of dental visits } \\
\hline & At least once per year & 33.5 \\
\hline & At least once each 2 years & 14.5 \\
\hline & Problems-related visits & 52.0 \\
\hline CLINICAL VARIABLES & Mean & Standard deviation \\
\hline $\mathrm{N}^{\mathrm{o}}$ of healthy non-restored teeth & 17.9 & 5.6 \\
\hline $\mathrm{N}^{\mathrm{o}}$ of natural standing teeth & 26.5 & 4.1 \\
\hline $\mathrm{N}^{\mathrm{o}}$ decayed teeth & 3.2 & 2.5 \\
\hline $\mathrm{N}^{\mathrm{o}}$ healthy filled teeth & 4.3 & 3.5 \\
\hline $\mathrm{N}^{\mathrm{o}}$ of missing teeth & 3.2 & 3.6 \\
\hline $\mathrm{DMFT}^{\mathrm{b}}$ & 10.7 & 4.9 \\
\hline $\mathrm{N}^{\circ}$ of replaced teeth & 1.3 & 2.9 \\
\hline $\mathrm{N}^{\circ}$ of occlusal units & 6.4 & 2.2 \\
\hline $\mathrm{N}^{\circ}$ of aesthetic units & 5.8 & 0.9 \\
\hline Sextants coded as $\mathrm{CPI}=0$ & 3.1 & 2.2 \\
\hline Sextants coded as $\mathrm{CPI}=1$ & 0.9 & 1.4 \\
\hline Sextants coded as $\mathrm{CPI}=2$ & 0.5 & 0.8 \\
\hline Sextants coded as $\mathrm{CPI}=3$ & 1.1 & 1.6 \\
\hline Sextants coded as $\mathrm{CPI}=4$ & 0.1 & 0.5 \\
\hline
\end{tabular}

a Social Class was estimated in occupational terms as follows: High: skilled non-manual worker; Medium: skilled manual worker; Low: non-skilled manual worker.

b DMFT index: Sum of decayed, missed and filled permanent teeth.

*Mean age \pm standard deviation was $45.1 \pm 9.3$ years 
Table 2. Health-related absenteeism and perceived occupational role of the mouth among the sample $(\mathrm{n}=269)$.

\begin{tabular}{|c|c|c|c|}
\hline & $\%$ & \multicolumn{2}{|c|}{ Days of work loss per year } \\
\hline & & Mean & Standard deviation \\
\hline \multicolumn{4}{|l|}{ Health-related absenteeism in the previous year } \\
\hline No & 60.2 & 0.0 & 0.0 \\
\hline Yes & 39.8 & 5.4 & 21.4 \\
\hline \multicolumn{4}{|l|}{ Cause of absenteeism $(\mathrm{n}=108)$} \\
\hline Colds & 45.4 & 2.5 & 1.2 \\
\hline Musculoskeletal pathology & 23.1 & 33.9 & 45.8 \\
\hline Gastric disease & 6.5 & 5.6 & 10.8 \\
\hline Cardiovascular disease & 5.6 & 24.3 & 47.2 \\
\hline Headaches-depression & 5.6 & 8.8 & 17.7 \\
\hline Diagnostic tests & 3.7 & 1.0 & 0.0 \\
\hline Respiratory disease & 2.8 & 4.7 & 4.6 \\
\hline Dental disease & 2.8 & 4.0 & 3.0 \\
\hline Nephritic spasm & 1.9 & 11.0 & 14.1 \\
\hline Gynecologic & 1.9 & 180.0 & 0.0 \\
\hline Conjunctivitis & 0.9 & 7.0 & 0.0 \\
\hline \multicolumn{4}{|c|}{$\begin{array}{l}\text { How many times did you be absent from work because } \\
\text { own health-related problems }\end{array}$} \\
\hline None & 60.2 & 0.0 & 0.0 \\
\hline Once & 30.1 & 15.8 & 36.0 \\
\hline Twice & 7.1 & 7.7 & 14.0 \\
\hline Three or four times & 2.6 & 1.7 & 1.0 \\
\hline \multicolumn{4}{|c|}{$\begin{array}{l}\text { Do you think that mouth influences your occupational } \\
\text { performance? }\end{array}$} \\
\hline No & 37.5 & 7.5 & 27.2 \\
\hline Yes & 62.5 & 4.1 & 17.0 \\
\hline \multicolumn{4}{|l|}{ Why? $(\mathrm{n}=167)$} \\
\hline Because of the pain-related events & 61.7 & 2.9 & 10.2 \\
\hline Because of aesthetics reasons & 15.0 & 2.0 & 6.0 \\
\hline Because of comunicating reasons & 12.6 & 12.1 & 40.6 \\
\hline Because of the bad odour & 10.8 & 5.1 & 11.4 \\
\hline \multicolumn{4}{|c|}{$\begin{array}{l}\text { In the last year have you had difficulties in carring out } \\
\text { your work because of problems with the teeth, mouth or } \\
\text { dentures? }\end{array}$} \\
\hline No & 95.9 & 5.5 & 21.8 \\
\hline Yes & 4.1 & 2.0 & 2.3 \\
\hline
\end{tabular}

work absences (4 days on average) and only in $2.8 \%$ of participants. By contrast, most of workers $(62.5 \%)$ considered mouth to influence their occupational performance, mainly because of the pain-related events (61.7\%), but only $4.1 \%$ of workers reported difficulties in carrying out their work in the last 12 months. Almost 10\% of workers were absent from work twice or more times in the previous year. The total days lost (TDL) and the average of days lost per 100 workers during the last year (TDL-100) are depicted within causes in figure 1 . The major cause of days loss was the musculoskeletal pathology (mainly low back pain, but also cervical pain) spending 814 days of work within the whole sample and being estimated to affect 315 working days per each 100 workers.

\section{- Modulating factors}

For perceiving that mouth affect the occupational performance of the worker, some modulating factors were arisen by Chi-Squared Test (Table 3). Females $(\mathrm{RR}=1.3)$, participants attending regular dental visits $(\mathrm{RR}=1.4)$ and denture wearers $(R R=2.5)$ were shown to have significantly higher risk of perceiving an occupational of the mouth. Also those participants reporting difficulties in chewing were also at higher risk than counterparts. Some clinical factors were also underlying this perception (Table 4). Workers considering the occupational role of the mouth had significantly less occlusal units, less healthy non-restored teeth, less natural standing teeth; and more missing teeth, more replaced teeth, more healthy restored teeth and more DMFT index. However subjects perceiving an occupational role of the mouth had better periodontal health. 


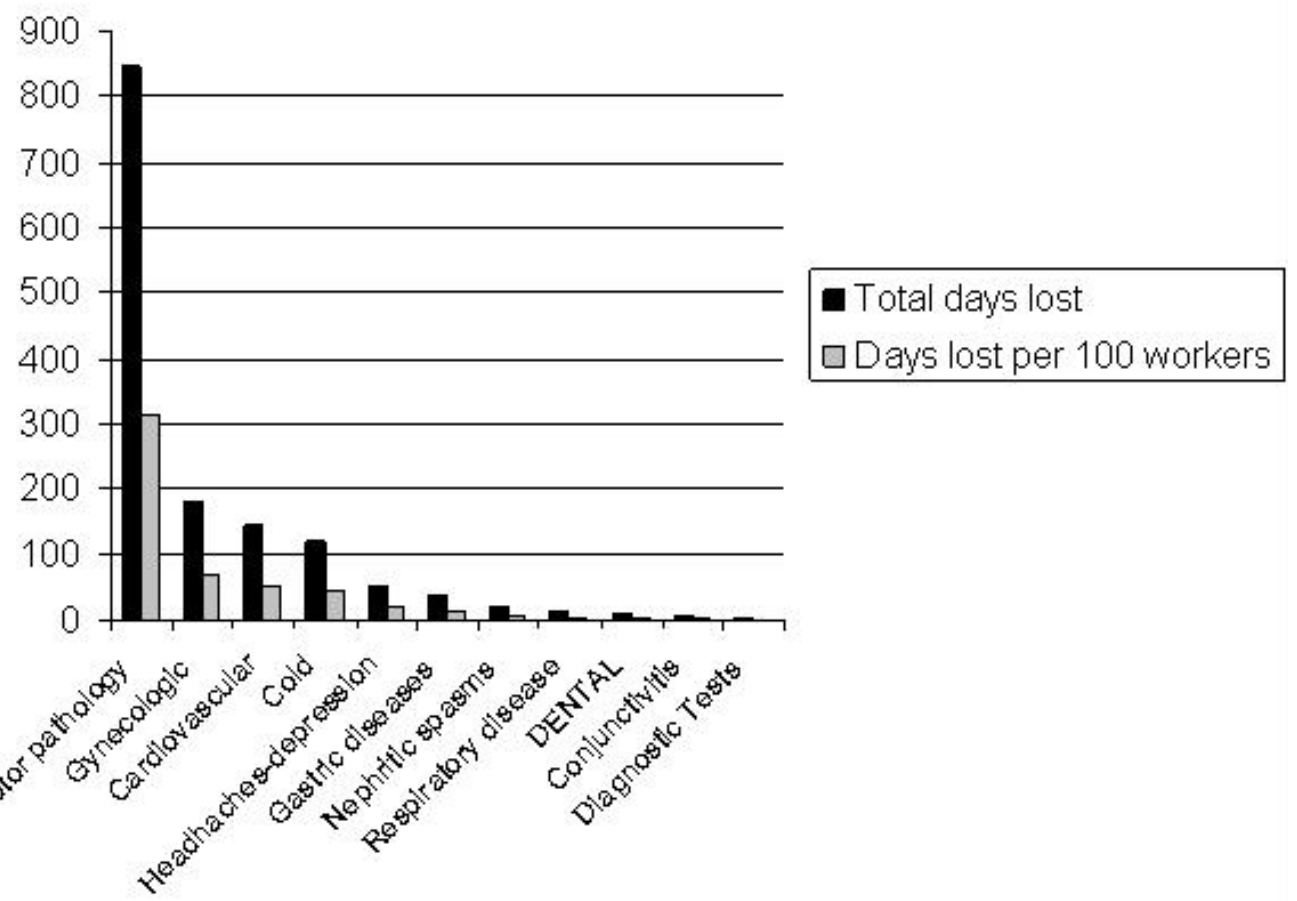

Fig. 1. Total days lost and total days lost per 100 workers within the sick leave causes in the past year $(n=269)$.

Table 3. Modulating factors of perceiving that mouth influences the occupational performance $(n=269)$.

\begin{tabular}{|c|c|c|c|c|}
\hline MODULATING FACTORS & $\mathrm{n}$ & $\begin{array}{c}\text { \% subjects perceiving an } \\
\text { occupational role of the mouth }\end{array}$ & RR & Odds Ratio \\
& & & & \\
\hline Sex & & & & $0.3-0.9$ \\
\hline Female & 147 & 68.7 & 1.3 & $1.0-1.7$ \\
\hline Male & 122 & 54.9 & 0.7 & $0.6-0.9$ \\
\hline Pattern of dental visits** & & & & $1.2-3.2$ \\
\hline Regularly & 129 & 70.5 & 0.7 & $1.1-1.9$ \\
\hline Problem-based & 140 & 55.0 & & $0.6-0.9$ \\
\hline Chewing difficulties* & & & 0.9 & $0.1-0.8$ \\
\hline Never & 235 & 59.6 & 2.7 & $0.8-1.0$ \\
\hline Yes, at least sometimes & 33 & 81.8 & & $1.2-6.4$ \\
\hline Prosthetic status* & & & 0.9 & $0.1-1.0$ \\
\hline Dentate & 243 & 60.5 & 2.5 & $0.9-1.0$ \\
\hline Denture wearers & 26 & 80.8 & $1.0-6.5$ \\
\hline
\end{tabular}

* Chi Square Test is significant at $\mathrm{p}<0.05$ level.

** Chi Square Test is significant at $\mathrm{p}<0.01$ level.

RR: Relative Risk 
Table 4. Modulating clinical factors of the occupational role of the mouth $(n=269)$.

\begin{tabular}{|c|c|c|c|c|}
\hline & $\begin{array}{l}\text { Do you think that } \\
\text { mouth influences } \\
\text { your occupational } \\
\text { performance? }\end{array}$ & Mean & $\begin{array}{l}\text { Standard } \\
\text { deviation }\end{array}$ & $\begin{array}{l}\text { Student T Test } \\
\text { comparisons }\end{array}$ \\
\hline \multicolumn{5}{|l|}{ Occlusal Units } \\
\hline & Yes & 6.1 & 2.2 & \multirow{2}{*}{$\begin{array}{l}\mathrm{T}=-2.472 \\
\mathrm{p}=0.01\end{array}$} \\
\hline & No & 6.8 & 2.1 & \\
\hline \multicolumn{5}{|l|}{$\begin{array}{l}\text { Healthy non-restored } \\
\text { teeth }\end{array}$} \\
\hline & Yes & 17.0 & 5.4 & \multirow{2}{*}{$\begin{array}{l}\mathrm{T}=-3.389 ; \\
\mathrm{p}=0.001\end{array}$} \\
\hline & No & 19.3 & 5.6 & \\
\hline \multicolumn{5}{|l|}{ Standing natural teeth } \\
\hline & Yes & 26.0 & 4.5 & \multirow{2}{*}{$\begin{array}{l}\mathrm{T}=-2.362 \\
\mathrm{p}=0.02\end{array}$} \\
\hline & No & 27.2 & 3.0 & \\
\hline \multicolumn{5}{|l|}{ Healthy restored teeth } \\
\hline & Yes & 4.7 & 3.5 & \multirow{2}{*}{$\begin{array}{l}\mathrm{T}=2.555 \\
\mathrm{p}=0.01\end{array}$} \\
\hline & No & 3.6 & 3.3 & \\
\hline \multicolumn{5}{|l|}{ Missing teeth } \\
\hline & Yes & 3.6 & 4.0 & \multirow{2}{*}{$\begin{array}{l}\mathrm{T}=2.648 \\
\mathrm{p}=0.01\end{array}$} \\
\hline & No & 2.6 & 2.5 & \\
\hline \multicolumn{5}{|l|}{ Replaced missing teeth } \\
\hline & Yes & 1.6 & 3.4 & \multirow{2}{*}{$\begin{array}{l}\mathrm{T}=2.666 ; \\
\mathrm{p}=0.01\end{array}$} \\
\hline & No & 0.8 & 1.5 & \\
\hline \multicolumn{5}{|l|}{ Sextants CPI $=0$} \\
\hline & Yes & 3.5 & 2.1 & \multirow{2}{*}{$\begin{array}{l}\mathrm{T}=3.227 \\
\mathrm{p}=0.001\end{array}$} \\
\hline & No & 2.6 & 2.3 & \\
\hline \multicolumn{5}{|l|}{ Sextants CPI $=3$} \\
\hline & Yes & 0.8 & 1.3 & \multirow{2}{*}{$\begin{array}{l}\mathrm{T}=-3.864 ; \\
\mathrm{p}<0.001\end{array}$} \\
\hline & No & 1.6 & 2.0 & \\
\hline \multicolumn{5}{|l|}{ Sextants CPI $=4$} \\
\hline & Yes & 0.1 & 0.3 & \multirow{2}{*}{$\begin{array}{l}\mathrm{T}=-2.519 ; \\
\mathrm{p}=0.01\end{array}$} \\
\hline & No & 0.2 & 0.6 & \\
\hline \multicolumn{5}{|l|}{ DMFT $^{\mathrm{a}}$} \\
\hline & Yes & 11.6 & 4.9 & \multirow{2}{*}{$\begin{array}{l}\mathrm{T}=4.065 \\
\mathrm{p}<0.001\end{array}$} \\
\hline & No & 9.2 & 4.7 & \\
\hline
\end{tabular}

a DMFT index: Sum of decayed, missed and filled permanent teeth.

\section{Discussion}

This study was, to our knowledge, the first focussing on the occupational role of the mouth among Spanish workers. However as it was carried out in a specific region of Spain and the sample size is not large enough, it could not represent the wide range of Spanish population values. Nevertheless in clinical terms the oral health status of this sample is comparable with that reported in the last National Oral Health Survey, for such age and socio-occupational group (1). Thus, it should be considered a preliminary approach which should be evaluated in large epidemiological studies because the National Statistical Institute does not offer data about the casual entity or days loss of the sick leave reported in the last survey performed in 2006 (6).
Within the main findings of this study it should be noted that mayor causes of sick leaves are pain-related (Table 2 and Figure 1), and mainly on the musculoskeletal system, in agreement with other authors (7). Moreover, among this aetiological entity, the most prevalent condition is the low back pain, which has reached epidemic proportions in the industrialized nations (8). This is a chronic pain condition which will be relapsed in relatively short periods (9) and will bring out new work absents periodically. The database of the National Statistical Institute (6) stated that during the year 2005, 5.5 million of workers were attended for emergency health services in 2005 , and $50 \%$ of the workers that have consumed any drug in the previous two weeks were directed toward alleviating pain. 
However dental conditions do not result in work disability for a majority of participants (Table 2), and for those who report work absences the impact is not large (4 days per year as average), representing less than $1 \%$ of the days loss among workers (Figure 1). This suggests that work disability in terms of days loss is not a sensitive indicator of the social impact of dental disease because of its limited variation among population (2). It is also likely that work absence underestimates other dimensions of work disability such as reduced productivity while present at work. In fact, most of workers considered that mouth influences their occupational performance, and mostly because of pain-related episodes (Table 2). It is also noteworthy that workers reporting mouth influence in their work have significantly poorer oral health than counterparts (Table 4). This fact was presumably based on past episodes of dental disease, because denture wearers and those reporting chewing difficulties have more than twice higher risk of perceiving the occupational role of the mouth than counterparts (Table 3). Females and those workers attending regularly to dental visits are also at higher risk of perceived the occupational role of the mouth. Women compared with men have been generally considered to have higher oral impact (10) and also higher sickness absence rates (11, 12). The workers visiting regularly the dentist are likely to perceive the importance of the oral health maintenance as essential for physical, psychological and social functioning. And this fact could explain why the periodontal health of those perceiving the occupational role of the mouth is much better (Table 4).

Dental disease, in spite of being a chronic condition because of its infectious nature, it advances generally in a slow manner for long bearable periods with few episodic acute problems which will be fully alleviated after treatment, thus it does not seem to be a major cause of occupational disturbance. Major concerns in Public Health are pointed to the chronic conditions of high prevalence among general population (as musculoskeletal pathology), because of the high resource consumption and the well-documented occupational impact (13).

Studies focussing on the patient perception of their sick leave are scarce (14) but it should be of paramount importance in Health Planning Policies (15) although dental disease have demonstrated to be a minor occupational cause of sick leave in this exploratory study as reported several authors $(2,3)$.

\footnotetext{
References

References with links to Crossref - DOI

1. Bravo M, Cortés J, Casals E, Llena C, Almerich-Silla JM, Cuenca E. Basic oral health goals for Spain 2015/2020. Int Dent J. 2009;59:78-82.

2. Reisine ST. Dental disease and work loss. J Dent Res. 1984;63:115861.

3. Gift HC, Reisine ST, Larach DC. The social impact of dental problems and visits. Am J Public Health. 1992;82:1663-8.

4. Jack SS, Ries PW. Current estimates from the National Health In-
}

terview Survey: United States, 1979. Vital Health Stat 10. 1981;10:1121.

5. Miller J. Waste of dental pain. Int Dent J. 1978;28:66-71.

6. Instituto Nacional de Estadística [www.ine.es]. Madrid: INE; 2010 (acceded July-2000). http://www.ine.es/jaxi/menu.

do? type $=$ pcaxis \&path $=/ \mathrm{t} 15 / \mathrm{p} 419 \&$ file $=$ inebase $\& \mathrm{~L}=0$

7. Sáinz de Murieta E, Fernández Baraibar J, Pascual I, Mena A, Martínez-Zubiri A, Condón MJ. Occupational disability due to locomotor pathology in the Foral Community of Navarra. Epidemiological aspects. An Sist Sanit Navar. 2005;28:83-92.

8. Nachemson A. Chronic pain--the end of the welfare state? Qual Life Res. 1994;3 Suppl 1:S11-7.

9. Badley EM, Rasooly I, Webster GK. Relative importance of musculoskeletal disorders as a cause of chronic health problems, disability, and health care utilization: findings from the 1990 Ontario Health Survey. J Rheumatol. 1994;21:505-14.

10. Montero J, Bravo M, Albaladejo A. Validation of two complementary oral-health related quality of life indicators (OIDP and OSS $0-10$ ) in two qualitatively distinct samples of the Spanish population. Health Qual Life Outcomes. 2008;6:101.

11. Bekker MH, Rutte CG, van Rijswijk K. Sickness absence: A gender-focused review. Psychol Health Med. 2009;14:405-18.

12. Laaksonen M, Martikainen P, Rahkonen O, Lahelma E. Explanations for gender differences in sickness absence: evidence from middle-aged municipal employees from Finland. Occup Environ Med. 2008;65:325-30.

13. Diaz-Ledezma C, Urrutia J, Romeo J, Chelen A, GonzálezWilhelm L, Lavarello C. Factors associated with variability in length of sick leave because of acute low back pain in Chile. Spine J. 2009;9:1010-5.

14. Norrmén G, Svärdsudd K, Andersson DK. How primary health care physicians make sick listing decisions: the impact of medical factors and functioning. BMC Fam

Pract. 2008;9:3.

15. Krause N, Dasinger LK, Deegan LJ, Rudolph L, Brand RJ. Psychosocial job factors and return-to-work after compensated low back injury: a disability phase-specific analysis. Am J Ind Med. 2001;40:374-92. 